\title{
Vascular dementia and the cholinergic pathways
}

\author{
Eliasz Engelhardt ${ }^{1}$, Denise Madeira Moreira ${ }^{2}$, Jerson Laks ${ }^{3}$
}

\begin{abstract}
Vascular cognitive impairment/vascular dementia have been the subject of a large number of studies, due to their high prevalence and broad preventive and compensatory therapeutic potential. The knowledge of the cerebral anatomy correlated to the vascular territories of irrigation enables understanding of clinical manifestations, as well as classification into the several types of syndromic presentations. The central cholinergic system exercises important neuromodulatory functions on cerebral circuits related to cognitive and behavioral integration, as well as on vasomotor control related to cerebral blood flow adjustments. The acquisition of data on the anatomy of the cholinergic pathways, including the localization of the nuclei of the basal prosencephalon and the routes of their projections, established an important milestone. The knowledge of the vascular distribution and of the trajectories of the cholinergic pathways allows identification of the strategic points where a vascular lesion can cause interruption. The ensuing denervation leads to cholinergic hypofunction in the involved territories. This information proves important to better evaluate the sites of vascular lesions, emphasizing their strategic localizations in relation to the cholinergic pathways, and offering more robust foundations for treatment aiming at enhancing cholinergic activity.
\end{abstract}

Key words: anatomy, vascular dementia, cognitive impairment, cholinergic fibers.

\section{Demência vascular e as vias colinérgicas}

Resumo - Comprometimento cognitivo vascular/demência vascular vem sendo objeto de numerosos estudos, levando em conta sua alta prevalência e as amplas possibilidades terapêuticas preventivas e compensatórias. O conhecimento da anatomia cerebral correlacionado ao dos territórios vasculares de irrigação permite a compreensão das manifestações clínicas, assim como a classificação dos diversos tipos de apresentações sindrômicas. O sistema colinérgico central exerce funções neuromoduladoras importantes dos circuitos relacionados à integração cognitiva e comportamental, além do controle vasomotor relacionado aos ajustes do fluxo sanguíneo cerebral. A obtenção de dados sobre a anatomia das vias colinérgicas, incluindo a localização dos núcleos do prosencéfalo basal e os trajetos das suas projeções, estabeleceu um marco importante. O conhecimento da distribuição vascular e do percurso das vias colinérgicas permite identificar pontos estratégicos onde a lesão vascular pode causar sua interrupção. A desnervação que se segue causa hipofunção colinérgica dos territórios acometidos. Essas informações são importantes para melhor avaliar os locais das lesões vasculares, enfatizando suas localizações estratégicas em relação às vias colinérgicas, oferecendo, desse modo, bases mais sólidas para o tratamento que visa aumentar a atividade colinérgica.

Palavras-chave: anatomia, demência vascular, comprometimento cognitivo, fibras colinérgicas.

The study of cholinergic hypofunction in Alzheimer's disease $(\mathrm{AD})$ is already more then two decades old, and has recently been extended to other dementing illnesses, such as the Lewy body diseases (dementia with Lewy bodies, dementia and Parkinson's disease) and vascular dementia (VaD). This knowledge underpins the widely known cholinomimetic treatment strategy, with the effi- cacious use of cholinesterase inhibitors ${ }^{1-4}$. Degeneration of the cholinergic nuclei of the basal prosencephalon (BP) and the derangement of their projections making up the cholinergic pathways can be seen in several primary dementing diseases.

Lesions of the $\mathrm{BP}$ and/or of the cholinergic pathways can be found at varied points of their course in VaD. The

${ }^{1} \mathrm{MD}, \mathrm{PhD}$, Cognitive and Behavioral Neurology Unit-INDC/UFRJ. ${ }^{2} \mathrm{MD}, \mathrm{PhD}$, Neuroradiology Unit-INDC/UFRJ, Radiology Unit of PróCardíaco-RJ Hospital. ${ }^{3} \mathrm{MD}$, $\mathrm{PhD}$, Coordinator of CDA-IPUB/UFRJ.

Dr. Eliasz Engelhardt - Av. Nossa Senhora de Copacabana, 749/708 - 22050-000 Rio de Janeiro RJ - Brazil. E-mail: eliasz @centroin.com 
same can be seen in mixed presentations, the most commonly described being $\mathrm{AD}+\mathrm{CVD}$ and $\mathrm{MD}(\mathrm{AD}+\mathrm{VaD})^{5}$.

The knowledge of the cholinergic system, both in normal and pathological states, is important to fully understand how the cholinergic treatment strategy works in $\mathrm{VaD}$ and what benefits it offers.

\section{The cholinergic nuclei of the basal prosencephalon}

The central cholinergic system is made up of several clusters of neurons distributed across different levels of the brain. The BP lies in the basal part and comprises four clusters or groups of cholinergic neurons, the large nucleus basalis of Meynert (nbM) being among them. The others include the medial nucleus of the septum $(\mathrm{nmS})$ and the nuclei of the diagonal band of Broca, along with the vertical (ndbBvl) and the horizontal (ndbBhl) limbs ${ }^{6-7}$.

The groups of cholinergic neurons in these nuclei are named according to the $\mathrm{Ch}$ nomenclature, and are found in $\mathrm{nmS}$ (Ch1), in ndbBvl (Ch2), in ndbBhl (Ch3), and in $\operatorname{nbM}(\mathrm{Ch} 4)^{6,8}$.

The nmS plus ndbBvl comprise about 20000 neurons, with 3200 cholinergic neurons, in each hemisphe$\mathrm{re}^{9-10}$. The nbM has about 200000 neurons in each hemisphere, subdivided into sectors related with particular cortical areas, in approximately a mediolateral and anteroposterior topography ${ }^{11-13,6,14-15}$.

All cholinergic neurons express acetylcholinesterase (AChE) and choline acetyltransferase (ChAT). The Ch1Ch4 clusters differ by the presence of neurons (about $90 \%$ ) containing the nerve growth factor receptor (NGFr), tirosine kinase (TRKa) and the neurotrophine receptor (p75NTR), not found in cholinergic neurons at other levels ${ }^{6}$.

\section{The cholinergic system and its functions}

The central cholinergic system exercises important functions including neuromodulation of brain circuits related to cognitive and behavioral integration ${ }^{16-20}$ and to vasomotor control.

Vasomotor control is related to modulation of brain blood flow, exerted through two mechanisms:

(i) circumscribed enhancement of perfusion related to increased neural activity in a given area caused by cholinergic stimulation, corresponding to 'functional hyperemia' resulting from neurovascular metabolic coupling ${ }^{21}$ and

(ii) vasodilator action on arteries of varied caliber, mainly on terminal ramifications (arterioles, capillaries) ac- complished through muscarinic receptors localized close to astrocytic terminations (gliovascular complexes) with liberation of nitric oxide to the smooth muscular fibers and pericytes ${ }^{22-25}$.

Vasomotor control has been studied in animal models, where vasodilatation was shown by cholinergic stimulation $^{22,26-29}$. An increase of perfusion was also seen in normal subjects and patients with $\mathrm{AD}$ or $\mathrm{VaD}$ with PET and SPECT imaging related to cholinergic intervention (use of cholinesterase inhibitors) ) $^{5,30-34}$.

Thus, this double activity, tissular and vascular, makes the cholinergic system important in normal functional condition. On the other hand, its hypofunction becomes an important target for interventions aiming to enhance its modulatory activity.

\section{The anatomy of the cholinergic pathways}

The projections from the $\mathrm{BP}$ cholinergic groups are directed toward several subcortical and cortical brain regions $s^{6,8-10,12,35-39}$.

The projections to the hippocampal formation and entorhinal cortex originate mainly from $\mathrm{Ch} 1-\mathrm{Ch} 2$ and have a route that accompanies the fornix. The terminals reach mainly the CA2-CA4 sectors of the hippocampus and the dentate gyrus, with a lesser density to sector CA1 and subiculum.

The Ch3 group is directed to olfactory areas, reached through the medial prosencephalic fascicle.

The projections to other regions of the cortex originate in the $\mathrm{Ch} 4$ group and constitute two bundles, the medial and the lateral. Fibers detach from these bundles and supply subcortical regions and cerebral cortex.

The medial cholinergic pathway originates from the $\mathrm{nbM}$, passes through the white matter of the straight and medial orbital gyri, around the rostrum of the corpus callosum and accompanies the cingulum bundle until the splenium, where it continues to the retrosplenial white matter. This pathway supplies ramifications to the medial orbitofrontal, subcallosal, cingulate, pericingulate, and retrosplenial cortical regions.

The lateral cholinergic pathway arises from the $\mathrm{nbM}$ and forms a compact bundle that subdivides in the capsular and perisylvian divisions that run through the external capsule and the claustrum, ramify widely in the centrum semiovale and subcortical white matter, and distribute fibers to the inferior frontal, frontoparietal operculum, temporal, insular, and para-hippocampal neocortex. The amygdala also receives fibers from the lateral pathway.

The cortical layers of all cytoarchitectonic regions present a dense cholinergic innervation. The density of 
Table 1. Brain cholinergic system - cholinergic groups, main projections and most important destinations of the basal prosencephalon.

\begin{tabular}{llll}
\hline Basal prosencephalon - nuclei & & Bundles/fascicles & Destination \\
\hline $\begin{array}{lll}\text { Medial nucleus of septum (Ch1) } \\
\text { nucleus of diagnonal band of Broca - }\end{array}$ & ndbBvl & fornix & hippocampal formation \\
vertical limb (Ch2) & & & entorhinal cortex \\
& & medial prosencephalic & hypothalamus \\
Nucleus of the diagonal band of Broca - & ndbBhl & medial prosencephalic & olfactory bulb \\
horizontal limb (Ch3) & & & \\
basal nucleus of Meynert (Ch4) & nbM & ansa peduncularis & amygdala \\
& & (ventral amigdalofugal) & \\
& medial pathway & alo- and mesocortex \\
& & medial orbitofrontal, subcallosal, cingulate, \\
& & & pericingulate, retrosplenial \\
& & lateral pathway & neocortex \\
& & inferior frontal, dorsal frontoparietal, frontoparietal
\end{tabular}

Figure 1. Basal prosencephalon and projections.
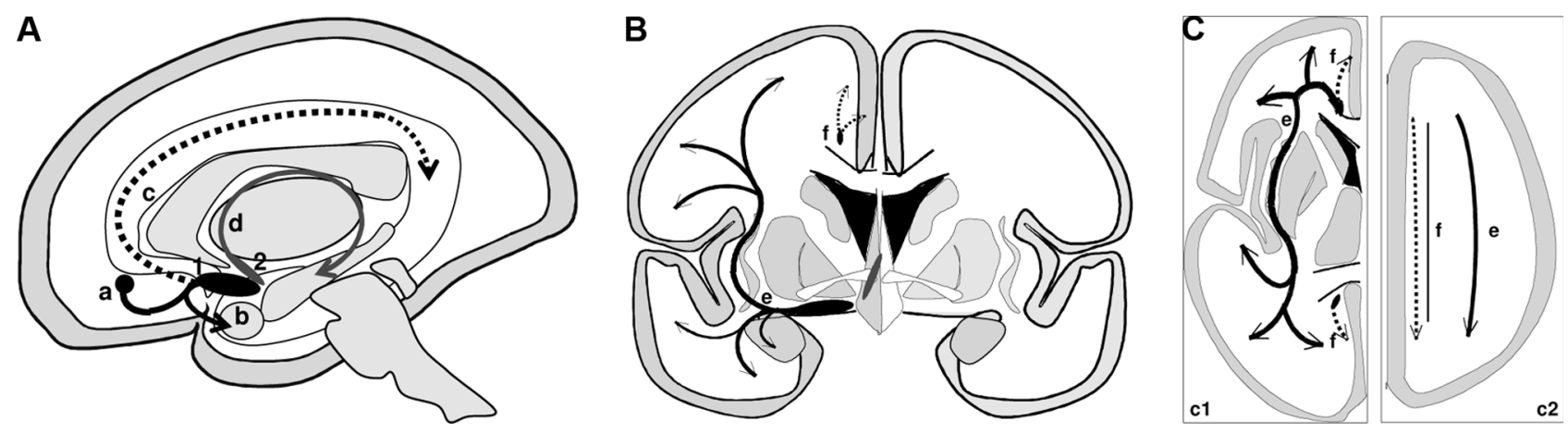

(A) Sagital scheme of the brain to localize the nuclei of BP and their main projections. (B) Coronal schema with localization of medial and lateral cholinergic pathways. (C) Axial schemata, two levels (c1, basal ganglia level; c2, supracallosal level), with localization of medial and lateral cholinergic pathways. $1=n m S(\mathrm{Ch} 1)+\mathrm{ndbBvl}(\mathrm{Ch} 2) ; 2=\mathrm{nbM}(\mathrm{Ch} 4)$. a) lateral pathway projection to the amygdala; b) lateral pathway, initial part of the main projection; c) medial pathway and its course in the cingulum; d) septo-hippocampal projection; e) lateral path (black-continuous) in its external capsuleclaustrum course; f) medial path (black-interrupted) in its cingulum course.

the cholinergic axons is higher in the more superficial cortical layers (I, II, and superior parts of layer III). There is a significant difference in the global density of the cholinergic axons among the several cytoarchitetonic regions. The highest fiber density is observed in the central limbic structures, such as the hippocampal formation and amygdala, followed by the cortical paralimbic areas, entorhinal and cingulate cortex; the cholinergic innervation of the unimodal and heteromodal associative areas is of intermediary density, while that of the primary sensory areas is the lowest ${ }^{6,12,18}$ (Table 1, Figures 1 and 2). The cortical cholinergic axons are mainly amyelinic and establish symmetric and asymmetric synapses with a large number of cortical and subcortical neurons. It is likely that part of the released ACh and the action it exerts is extra-synaptic, reaching neurons and neuroglia relatively distant from 
Table 2. Territories of the cerebral arteries related to cholinergic structures or their routes.

\begin{tabular}{ll}
\hline Artery & Territory \\
\hline ACA & BP (Ch3 and Ch4-pt), septal region, frontal (basal), subcallosal area, cingulum, centrum semiovale (pt) \\
MCA & BP (Ch4-pt), claustrum, external and extreme capsules, centrum semiovale (pt) \\
PCA & centrum semiovale (pt) \\
AChA & BP (pt) \\
ACoA & BP (Ch1 e Ch2), septum, subcallosal area, cingulum (anterior pt), fornix (columns) \\
PCoA &
\end{tabular}

ACA, anterior cerebral artery; MCA, middle cerebral artery; PCA, posterior cerebral artery; AChA, anterior choroidal artery; ACoA, anterior communicating artery; PCoA, posterior communicating artery; BP, basal prosencephalon; pt, part.

the site of neurotransmitter release by diffusion (volume transmission $)^{40-43}$.

\section{The cholinergic pathways and the cerebral vascular territories}

The cholinergic projections of the septo-hippocampal path present a fairly compact constitution, running through the fornix to reach the hippocampal formation. The Meynert-cortical projections present a relatively compact origin, but once outside the basal ganglia territory, at the level of the centrum semiovale, the lateral pathway presents a fanlike distribution to reach their destination areas, while the medial pathway runs mainly through the cingulum and distributes ramifications along its route ${ }^{38}$.

The main cerebral arteries - anterior cerebral artery (ACA), middle cerebral artery (MCA), anterior communicating artery $(\mathrm{ACoA})$, posterior communicating artery (PCoA), anterior choroidal artery $(\mathrm{AChA})$ - provide irrigation of the territories where the cholinergic projections travel $^{5,46-51}$ (Table 2, Figure 2).

\section{The cholinergic pathways and cerebrovascular disease}

Ischemic or hemorrhagic processes represent the several cerebrovascular pathologies that can cause tissue damage and interruption of the cholinergic pathways. The ischemic processes cause territorial infarcts, watershed infarcts, lacunes, white matter demyelination, affecting areas of varied $\operatorname{size}^{52-56}$. It is possible to localize the points where lesions can interrupt these pathways by considering the routes of the cholinergic pathways ${ }^{38}$ and the vascular territories (Table 2, Figure 2, Figure 3).

The lesions of the BP, severely affecting the septal area and/or the $\mathrm{nbM}$, can occur due to ischemia in the territories of the ACA, ACoA and MCA. The projection of the septal area to the hippocampal formation, via the fornix,
Figure 2. Coronal schema of the brain - the cholinergic pathways (left side) (medial path=black-interrupted; lateral path= black-continuous) and the limits of the main vascular territories (right side).

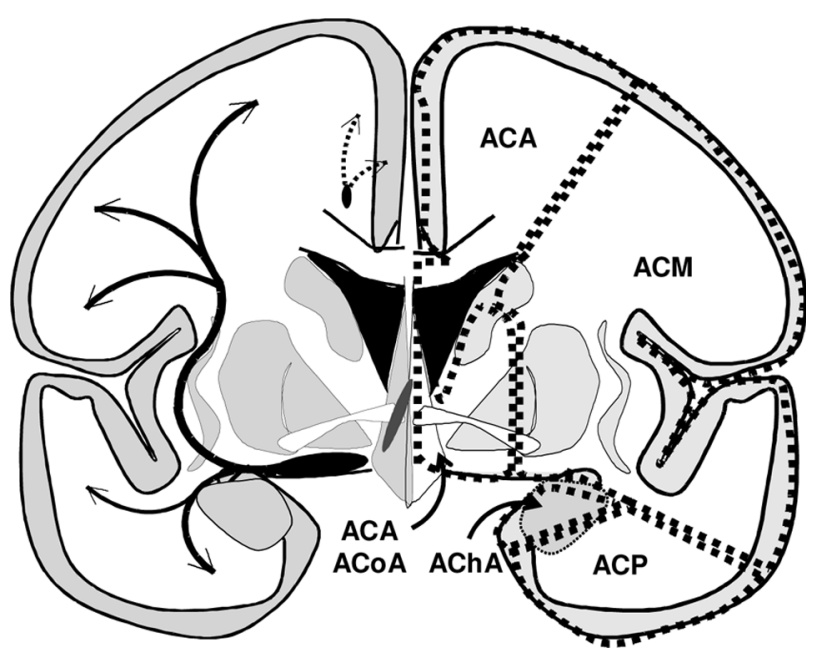

ACA, anterior cerebral artery; MCA, middle cerebral artery; PCA, posterior cerebral artery; $\mathrm{ACoA}$, anterior communicating artery; AChA, anterior choroidal artery.

can be interrupted by lesions in the territory of the ACoA. The interruption of the wide Meynert-cortical projections may stem from a variety of lesion sites. The main medial pathway can be interrupted at any point of its route in the cingulum due to pathology in the ACA and ACoA territories, while the ramifications of this pathway, with a more radiating distribution, can be injured in territories of the same arteries at a variety of points. The main lateral pathway can be affected in its sublenticular and paralenticular route (external capsule and claustrum) due to lesions in the territories of the ACA, ACoA and MCA, and its wide and fanlike course 


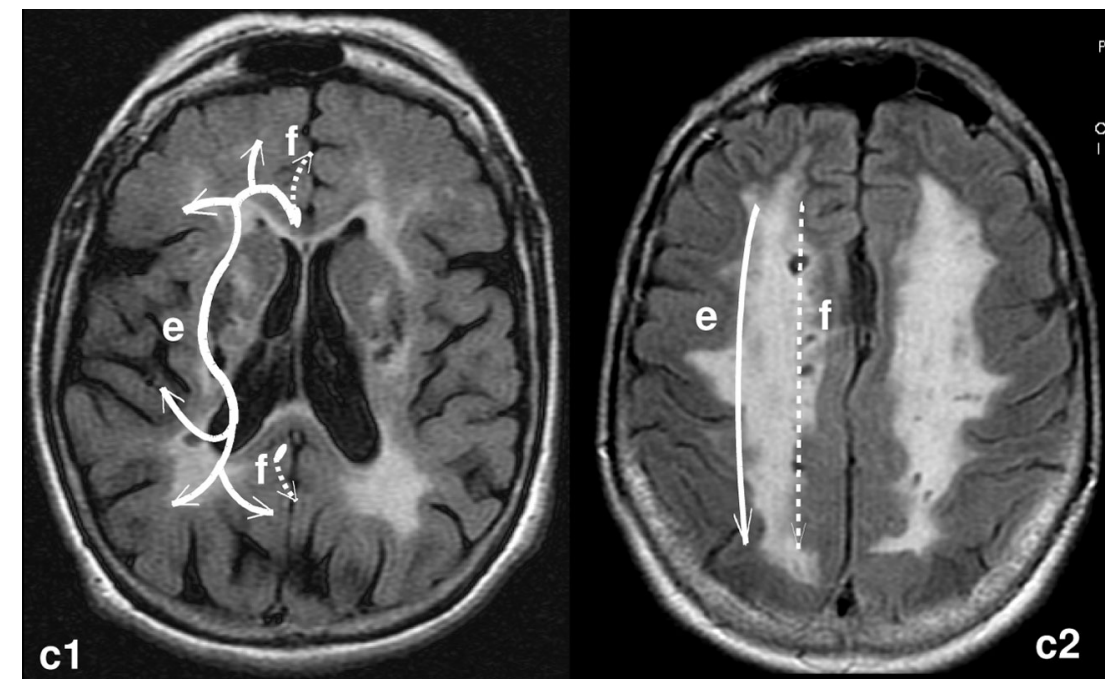

Figure 3. RM-FLAIR. Axial sections of the brain of a case with extensive subcortical demyelination. The cholinergic pathways are depicted to the left side (medial path= white -interrupted, lateral path $=$ white continuous) on two levels (similar to Figure 1C). can be affected in the white matter of the centrum semiovale, irrigated mainly by the ACA, MCA and PCA (Figure 2C, Figure 3).

Two neuropathologic studies indicate a relationship between CVD and the interruption of these pathways, besides the anatomic relations between the cholinergic pathways and the vascular territories.

One of these studies was conducted using brain tissue from a patient with CADASIL (cerebral autosomic dominant arteriopathy with subcortical infarcts and leucoencepalopathy), a disease that can be considered a model for pure CVD ( VaD). The material was stained with a histochemical technique to show AChE revealing cholinergic denervation in several cortical areas, except for the hippocampal formation and entorhinal cortex. Even in the more affected areas a number of AChE positive fibers were seen. The cholinergic neurons of the nbM were undamaged, as verified by techniques for NGFr and $\mathrm{AChE}^{57}$.

The other study was performed using brain tissue of patients with $\mathrm{VaD}$ of the Binswanger subtype. The material was stained with histochemical and imunnohistochemical techniques to show AChE and ChAT. This material revealed severe reduction of $\mathrm{AChE}$ and ChAT positive fibers in the external capsule and claustrum, in comparison to controls. The nbM had large neurons preserved, but showed some chromatolytic changes and numerical reduction.

A neuroimage-neuropathological correlation was possible for some of the patients. MRI showed hyperintensities in the frontal periventricular white matter, extending to the subinsular white matter (where the external capsule is found). The brains of the same patients at autopsy showed loss of myelin in the corresponding regions ${ }^{58}$. Therefore, underpinned by these two paradig- matic studies, we can state that CVD may cause interruption of segments of the cholinergic pathways, leading to denervation and consequent cholinergic hypofunction of the affected territories.

Cholinergic hypofunction, variable according to the lesioned segment of the cholinergic pathways, causes integrative dysfunction of the target brain structures and disturbances of vasomotor control with consequent reduction in brain blood flow of the affected areas ${ }^{5,59}$. These functional data gave rise to the proposal of a 'cholinergic neurovascular hypothesis' 22 .

Recently, two studies were dedicated to the relationship between the cholinergic pathways and the white matter hyperintensities, correlated to the clinical manifestations of $\mathrm{VCI} / \mathrm{VaD}$, with the aim of staging scales. These proposals relate the white matter lesions with their localization in relation to the cholinergic pathways. The staging was graduated according to the visually evaluated extension, and number of lesions localized, along the anatomical known routes of the cholinergic pathways. One of these rating scales classified the lesions in the cholinergic pathways as minimal (absence of lesions in $\mathrm{nbM}$ and absence of hyperintensities in medial pathway or external capsule), moderate (lesions in external capsule plus in lateral pathway) and severe (nbM infarction or external capsule plus lateral pathway hyperintensities or large hyperintensities in lateral pathway or hyperintensities in both lateral and medial pathways $)^{60}$. The other, more detailed rating, proposes an evaluation on 4 slices (low external capsule, high external capsule, corona radiata and centrum semiovale), separated into 10 regions. The severity of white matter lesions was visually rated on a 3-point scale (0-3) for each region, and weighted (1-4) to account for the decreasing concentration of choliner- 
gic fibers as they project and fan out in the white matter ${ }^{61}$. The results of these studies suggest that the localization of the hyperintensities in the white matter holds special importance, considering that some of these may occur at strategic points and may be related to measurable clinical manifestations $s^{60,61}$.

Thus, the knowledge of the anatomy of the cholinergic pathways and their relation to those vascular territories where an interruption can occur, allied to the consequent clinical manifestations, enable better evaluation of CVD clinical expression. It may also be able to lend a more solid basis for treatment strategies, such as the cholinergic approach.

\section{Conclusion}

CVD can cause clinical symptoms defining $\mathrm{VCI} / \mathrm{VaD}$ according to its extension and localization. Two mechanisms play a role: one corresponding to tissue lesions of cortical areas and subcortical regions, including white matter responsible for disconnection related manifestations, while the other is related to the interruption of the cholinergic pathways at various localizations along their routes, producing manifestations consequent to cholinergic denervation which result in a hypocholinergic state of the affected territories.

Knowledge of cognitive-behavioral and vasomotor functions of the cholinergic system, allied to that of the anatomical localization of the course of its pathways, is important to better assess the sites of vascular lesion. Such knowledge permits strategic points of the cholinergic pathways to be highlighted and provides more solid bases for use of cholinergic therapeutic strategies.

Acknowledgement - To Luzinete N.O. Alvarenga for editorial assistance.

\section{References}

1. Bartus RT, Dean RL, Beer, Lippa AS. The cholinergic hypothesis of geriatric memory dysfunction. Science 1982; 217:408-417.

2. Bartus RT. On neurodegenerative diseases, models, and treatment strategies: lessons learned and lessons forgotten a generation following the cholinergic hypothesis. Exp Neurol 2000;163:495-529.

3. Birks J. Cholinesterase inhibitors for Alzheimer's disease. Cochrane Database Syst Rev; 2006.

4. Engelhardt E, Brucki SM, Cavalcanti JLS, Forlenza OV, Laks J, Vale FAC. Tratamento da doença de Alzheimer: recomendações e sugestões do Departamento Científico de Neurologia Cognitiva e do Envelhecimento da Academia Brasileira de Neurologia. Arq Neuropsiquiatr 2005;63:1104-1112.
5. Román GC, Kalaria RN. Vascular determinants of cholinergic deficits in Alzheimer's disease and vascular dementia. Neurobiol Aging (in press).

6. Mesulam MM. Structure and function of cholinergic pathways in the cerebral cortex, limbic system, basal ganglia, and thalamus of the human brain. In: Bloom FE, Kupfer DJ, editors. Psychopharmacology: The Fourth Generation of Progress. New York: Raven Press; 1995:135-146.

7. Mufson EJ, Ginsberg SD, Ikonomovic MD et al. Human cholinergic basal forebrain: chemoanatomy and neurological dysfunction. J Chem Neuroanat 2003;26:233-242.

8. Nieuwenhuys R. Chemoarchitecture of the brain. Berlin: Springer-Verlag; 1985:7-11.

9. Gertz HJ, Cervos-Navarro J, Ewald V. The septo-hippocampal pathway in patients suffering from senile dementia of Alzheimer's type. Evidence for neuronal plasticity? Neurosc Lett 1987;76:228-232.

10. Fujishiro H, Umegaki H, Isojima D et al. Depletion of cholinergic neurons in the nucleus of the medial septum and the vertical limb of the diagonal band in dementia with Lewy bodies. Acta Neuropathol 2006;111:109-114.

11. Arendt T, Bigl V, Tennstedt A et al. Neuronal loss in different parts of the nucleus basalis is related to neuritic plaque formation in cortical target areas in Alzheimer's disease. Neuroscience 1985;14:1-14.

12. Geula C, Mesulam MM. Cholinergic Systems in Alzheimer's Disease. In: Terry RD, Katzman R, Bick KL, Sisodia SS, editors. Alzheimer Disease, 2nd ed, Philadelphia: Lippincott Williams \& Wilkins; 1999:269-292.

13. McGeer PL, McGeer EG, Suzuki J et al. Aging, Alzheimer's disease, and the cholinergic system of the basal forebrain. Neurology 1984;34:741-745.

14. Mesulam M, Geula C. Nucleus Basalis (Ch4) and cortical cholinergic innervation in the human brain: observations based on the distribution of acetylcholinesterase and choline acetyltransferase. J Comp Neurol 1988;275:216-240.

15. Page KJ, Sofroniew MV. The ascending basal forebrain cholinergic system. Prog Brain Res 1996;107:513-22.

16. Everitt B, Robbins TW. Central cholinergic systems and cognition. Ann Rev Psychol 1997;48:649-684.

17. Gold PE. Acetylcholine modulation of neural systems involved in learning and memory. Neurobiol Learn Mem 2003;80:194-210.

18. Mesulam M. The cholinergic lesion of Alzheimer's disease: pivotal factor or side show. Learn Mem 2004;11:43-49.

19. Minger SL, Esiri MM, McDonald B, et al. Cholinergic deficits contribute to behavioral disturbances in patients with dementia. Neurology 2000; 55:1460-1467

20. Sarter M, Bruno JP. Cognitive functions of cortical acetylcholine: toward a unifying hypothesis. Brain Res Brain Res Rev 1997; 23:28-46. 
21. Iadecola C. Neurovascular regulation in the normal brain and in Alzheimer's disease. Nat Rev Neurosci 2004;5:347360.

22. Claassen JAHR, Jansen WMM. Cholinergically mediated augmentation of cerebral perfusion in Alzheimer's disease and related cognitive disorders: The cholinergic-vascular hypothesis. J Gerontol Med Sci 2006;61:267-271.

23. Elhusseiny A, Cohen Z, Olivier A, et al. Functional acetylcholine muscarinic receptor subtypes in human brain microcirculation: identification and cellular localization. J Cer Bl Flow Metabol 1999;19:794-802.

24. Luiten PGM, de Jong Givan, der Zee EA, van Dijken H. Ultrastructural localization of cholinergic muscarinic receptors in rat brain cortical capillaries. Brain Res 1996; 720: 225-229.

25. Tong XK, Hamel E. Regional cholinergic denervation of cortical microvessels and nitric oxide synthase-containing neurons in Alzheimer's disease. Neuroscience 1999;92:163-174.

26. Barbelivien A, Bertrand N, Besret L, et al. Neurochemical stimulation of the rat substantia inominata increases cerebral blood flow (but not glucose use) through the parallel activation of cholinergic and non-cholinergic pathways. Brain Res 1999; 840:115-124.

27. Grantham C, Geerts H. The rationale behind cholinergic drug treatment for dementia related to cerebrovascular disease. J Neurol Sci 2002;203-4:131-136.

28. Sato A, Sato Y, Uchida S. Regulation of regional cerebral blood flow by cholinergic fibers originating in the basal forebrain. Int J Dev Neuroscience 2001;19:327-337.

29. Scremin OU, Li MG, Scremin AME et al. Cholinesterase inhibition improves blood flow in the ischemic cerebral cortex. Brain Res Bull 1997;42:59-70.

30. Blin J, Ivanoiu A, Coppens A, et al. Cholinergic neurotransmission has different effects on cerebral glucose consumption and blood flow in young normals, aged normals, and Alzheimer's disease patients. Neuroimage 1997;6:335-343.

31. Ceravolo R, Volterrani D, Tognoni G, et al. Cerebral perfusional effects of cholinesterase inhibitors in Alzheimer's disease. Clin Neuropharmacol 2004; 27:166-170.

32. Lojkowska W, Ryglewicz D, Jedrzejczak T, et al. The effect of cholinesterase inhibitors on the regional blood flow in patients with Alzheimer's disease and vascular dementia. J Neurol Sci 2003;216:119-126.

33. Lipczynska-Lojowska W, Ryglewicz D, Jedrzejczak T, et al. The effect of rivastigmine on cognitive functions and regional cerebral blood flow in Alzheimer's disease and vascular dementia: follow-up for 2 years. Neurol Neuroch Polska 2004;38:471-481.

34. Nobili F, Koulibaly M, Vitali P et al. Brain perfusion followup in Alzheimer's patients during treatment with acetylcholinesterase inhibitors. J Nucl Med 2002;43:983-990.
35. Kitt CA, Mitchell SJ, DeLong MR et al. Fiber pathways of basal forebrain cholinergic neurons in monkeys. Brain Res 1987; 406:192-206.

36. Mesulam MM, Hersh LB, Mash DC, Geula C. Differential cholinergic innervation within functional subdivisions of the human cerebral cortex: a choline acetyltransferase study. J Comp Neurol 1992;318:16-28.

37. Paré D, Smith Y, Parent A, Steriade M. Projections of brainstem core cholinergic and non-cholinergic neurons of cat to intralaminar and reticular thalamic nuclei. Neuroscience 1988;25:69-86.

38. Selden NR, Gitelman DR, Salamon-Murayama N et al. Trajectories of cholinergic pathways within the cerebral hemispheres of the human brain. Brain 1998;121:2249-2257.

39. Steriade M, Paré D, Parent A, Smith Y. Projections of cholinergic and non-cholinergic neurons of the brainstem core to relay and associational thalamic Nuclei in the cat and macaque monkey. Neuroscience 1988;25:47-67.

40. Descarries L, Gisiger V, Steriade M. Diffuse Transmission by Acetylcholine in the CNS. Progr Neurobiol 1997; 53:603625.

41. Sykova E. Extrasynaptic volume transmission and diffusion parameters of the extracellular space. Neuroscience 2004; 129: 861-876.

42. Sykova E. Glia and volume transmission during physiological and pathological states. J Neural Transm 2005;112:137147.

43. Zoli M, Agnati LF. Wiring and volume transmission in the central nervous system: the concept of closed and open synapses. Progr Neurobiol 1996; 49:363-380.

44. Engelhardt E, Moreira DM, Nacif MS, Moscovici M. As vias colinérgicas e a demência vascular. Rev Bras Neurol 2006; 42:43-52.

45. Shute CC, Lewis PR. The ascending cholinergic reticular system: neocortical, olfactory and subcortical projections. Brain 1967; 90:497-520.

46. Adams RD, Victor M. Cerebrovascular diseases. In: Adams RD, Victor M. Principles of neurology. 5th ed, New York: McGraw-Hill, 1993:669-748.

47. Biller J. Vascular syndromes of the cerebrum. In: Brazes PW, Masseur JC, Biller J, editors. Localization in clinical neurology. 2nd ed, Boston: Little, Brown and Co., 1990:429-455.

48. Krayenbühl HÁ, Yasargil MG. Cerebral angiography. 2th ed. Londres: Butterworths; 1968:20-84.

49. Salamon G. Atlas de la vascularisation arterielle du cerveau chez l'homme. Paris: Sandoz Editions; 1973.

50. Serizawa T, Saeki N, Yamaura A. Microsurgical anatomy and clinical significance of the anterior communicating artery and its perforating branches. Neurosurgery 1997;40:1211-1216.

51. Woolsey AT, Hanaway J, Gado MH. The brain atlas. 2nd ed., Hodoboken: Wiley; 2003. 
52. Chemerinski E, Robinson RG. The neuropsychiatry of stroke. Psychosomatics 2000;41:5-14.

53. Engelhardt E, Laks J, Cavalcanti JLS, Moreira DM, Madalen C. Demência vascular. Rev Bras Neurol 2004;40:5-26.

54. Erkinjuntti T. Clinicopathological study of vascular dementia. In: Prohovnik I, Wade J, Knezevic S, Tatemichi T, Erkinjuntti T, editors. Vascular dementia: current concepts, Chichester: Wiley; 1996:73-112.

55. Jellinger KA. The pathology of ischemic-vascular dementia: an update. J Neurol Sci 2002;203-204:153-157.

56. Markus HS. Cerebral perfusion and stroke. J Neurol Neurosurg Psychiatry 2004;75:353-361.

57. Mesulam M, Siddique T, Cohen B. Cholinergic denervation in a pure multi-infarct state. Neurology 2003; 60:1183-1185.
58. Tomimoto H, Ohtani R, Shibata M, Nakamura N. Loss of cholinergic pathways in vascular dementia of the Binswanger type. Dement Geriatr Cogn Disord 2005;19:282288.

59. Román GC. Cholinergic dysfunction in vascular dementia. Curr Psychiatry Rep 2005;7:18-26.

60. Swartz RH, Sahlas DJ, Black SE. Strategic involvement of cholinergic pathways and executive dysfunction: does location of white matter signal hypertensities matter? J Stroke Cerebrovasc Dis 2003;12:29-36.

61. Bocti C, Swartz RH, Gao FQ, et al. A new visual rating scale to assess strategic white matter hyperintensities within cholinergic pathways in dementia. Stroke 2005;36:21262131. 